\title{
Bioagriculture Outlier Elimination Based on 3D View of $X-Y$ Variance and Leverage Measurement
}

\author{
Weizheng Shen, Qingming Kong, Jianbo Wang, Nan Ji, and Zhongbin Su \\ School of Electrical and Information, Northeast Agricultural University, Harbin 150030, China \\ Correspondence should be addressed to Zhongbin Su; zhongbinsu@163.com
}

Received 22 September 2014; Accepted 29 December 2014

Academic Editor: Bo-Wei Chen

Copyright (c) 2015 Weizheng Shen et al. This is an open access article distributed under the Creative Commons Attribution License, which permits unrestricted use, distribution, and reproduction in any medium, provided the original work is properly cited.

\begin{abstract}
Aiming at effective outlier elimination in the biological near-infrared spectral and achieving high accuracy predictive modeling, this paper proposes a novel outlier elimination method based on $X-Y$ variance and leverage analysis. Firstly, the characters of nearinfrared spectral are summarized; then residual sample $X$-variance, leverage, and residual sample $Y$-variance are concatenated as a divergence measurement. We further compared the proposed method with $X-Y$ variance, Mahalanobis distance, and Hotelling $T^{2}$ statistical analysis; the experiment results demonstrate that the proposed methods have competitive outlier elimination and better performance in time complexity and accuracy. The proposed method can also be adopted for other outlier elimination tasks.
\end{abstract}

\section{Introduction}

In the past few years, quality safety of food and supplies is becoming increasingly severe in China with rapid advance of national economy [1-5]. Rapid detection of quality is getting higher in industrial manufacturing, agricultural production, and commercial popularizing. Near-infrared spectroscopy is paid close attention to as a new direction and method of rapid detection, which develops hugely in agriculture, food, medicine, chemical, and so forth because of its advantages of high analysis speed, efficiency, nonpollution, and easy online detection [6-15]. However, as a kind of indirect analysis technology, near-infrared spectroscopy needs to establish the analysis model between spectral information and the nature of the data samples, parse out the correlation between the various spectral information and sample properties, and use the resulting calibration model to predict unknown samples in order to achieve the purpose of rapid detection [16-20]. Therefore the accuracy of the selected data is to be able to achieve ideal to predict the results.

However, during the whole process of spectrum data collection, it is likely to cause model nonrepresentative such as outlier samples due to experimental errors or sample collection and classification of uneven [21-25]. The existence of the stray samples will be affected to some extent and even change the distribution trend of overall data; thus they affect the accuracy of the calibration model. So quick and efficient sample removed from the group is the key to establishing correction model. At present, several commonly used analysis methods are based on multivariate statistical analysis to judge whether a statistics is beyond a specific threshold [26-28] (beyond a certain threshold), which have a certain effect, but the tested samples after the replacement of material data method are not reliable and sometimes cannot get satisfactory results.

In this paper, on the basis of analyzing several kinds of methods, we put forward a method based on $X-Y$ (X represents the spectral information and $Y$ chemical representative sample number) variance VS leverage value method of $3 \mathrm{D}$ sample removed from the group, using residual sample $X$ variance, leverage (leverage value), and the residual sample $Y$ variance as three-axis direction through the $3 \mathrm{D}$ view overall to judge from soy oleic acid value model $[29,30]$ and wheat straw biomass model $[30,31]$ from the group of the distribution of the sample. By comprehensive comparison of $X-Y$ variance, Markova distance, and Hotelling $T^{2}$ statistics as the traditional method to sample out from the group, its effect is ascended and improved obviously by repeating many times in the 3D view out the analysis. Final calibration model soybean oil acid value model and wheat straw biomass model 
TABle 1: Sample distribution statistics.

\begin{tabular}{lcccc}
\hline Sample & Number & Minimum & Maximum & Average \\
\hline Wheat straw bran & 123 & 2.931 & 99.208 & 46.136 \\
Soybean acid value & 52 & 0.458 & 3.102 & 1.679 \\
\hline
\end{tabular}

TABLE 2: Wheat straw biomass sample classification statistics.

\begin{tabular}{lcccc}
\hline Sample classification & Number & Minimum $(\mathrm{mg} / \mathrm{g})$ & Maximum $(\mathrm{mg} / \mathrm{g})$ & Average $(\mathrm{mg} / \mathrm{g})$ \\
\hline Calibration set & 90 & 12.7043 & 98.7583 & 49.8357 \\
Validation set & 30 & 15.8331 & 94.0651 & 49.8755 \\
\hline
\end{tabular}

TABLE 3: Soybean oil acid sample classification statistics.

\begin{tabular}{lcccc}
\hline Sample classification & Number & Minimum $(\mathrm{mg} \mathrm{KOH} / \mathrm{g})$ & Maximum $(\mathrm{mg} \mathrm{KOH} / \mathrm{g})$ & Average $(\mathrm{mg} \mathrm{KOH} / \mathrm{g})$ \\
\hline Calibration set & 40 & 0.473 & 3.005 & 1.685 \\
Validation set & 10 & 0.563 & 2.827 & 1.681 \\
\hline
\end{tabular}

$R^{2}$ were promoted from $0.8653109,0.843431$ to upgrade to $0.966022,0.934227$. RSD (relative standard deviations) were also decreased to $5 \%$ and $8 \%$.

\section{Materials and Methods}

2.1. Samples Collection. Wheat straw and soybean oil were experimental verification objects, which measured wheat straw biomass (fermentation process) and soybean oil component in acid value, respectively. Wheat brans were collected from different places in Heilongjiang Province, whose total number was 123 . And samples of soybean oil were deployed by manufacturing enterprise in various acid values. KennardStone algorithm was used to calculate Euclidean distance among absorbance spectra of samples. In the meanwhile, the most representative samples were selected as calibration set and its sample distribution was as shown in Table 1 . The unit of soybean acid value is $\mathrm{mg} \mathrm{KOH} / \mathrm{g}$ which represents desired quality of potassium hydroxide in $1 \mathrm{~g}$ fat of free fatty acids. Unit of wheat bran straw biomass (fermenting microorganisms) is $\mathrm{mg} / \mathrm{g}$ which represents microbial cell density per unit volume. Its distribution of the sample is shown in Table 1; their sample classification is shown in Tables 2 and 3.

2.2. Spectral Acquisition. In the experiment using Thermo Antaris II near-infrared spectrometers scan for soybean oil and wheat bran, which range from $830 \mathrm{~nm}$ to $2500 \mathrm{~nm}$ $\left(12000 \mathrm{~cm}^{-1}-4000 \mathrm{~cm}^{-1}\right)$ the resolution of $8 \mathrm{~cm}^{-1}$. Respectively, using sweep surface mode of liquid transmission and integration ball, empty transparent glass is selected to contrast and air is used as a comparison object sphere scanning. Before sample surface scanning, we set the number of background scan 32 times and experiment scan 32 times. Its sample scan results as shown in Figure 1, as sequence is soybean oil and wheat straw biomass spectrum.

2.3. Samples' Chemical Calibration. (1) Oil samples are dissolved with mixed neutral alcohol-ether solvent; then free fatty acids are titrated with alkali standard solution.
According to the quality of oil and amount of alkali consumption, acid value is calculated. We need the following orders including reagent, instruments and appliances, and operation.

(1) Reagent. Consider the following:

the $0.1 \mathrm{~mol} / \mathrm{L} \mathrm{KOH}$ (or sodium hydroxide standard solution);

the neutral ether-ethanol $(2: 1)$ mixed solvent, with $0.1 \mathrm{~mol} / \mathrm{L}$ alkali to titrate to neutral before using; the $1 \mathrm{~g} / 100 \mathrm{~mL}$ indicator of phenolphthalein-ethanol.

(2) Instruments and Appliances. Consider the following:

the burette of 25 or $50 \mathrm{~mL}$;

the Erlenmeyer flask of $250 \mathrm{~mL}$;

the balance of sensitivity of $0.001 \mathrm{~g}$;

the volumetric flask, pipette, the weighing bottle, reagent bottle, a graduated flask, and beakers.

(3) Operational Approach. The main steps are as follows: firstly, uniform specimen $(3-5 \mathrm{~g})$ is weighed to inject into the conical flask. Secondly, neutral mixed solution $(50 \mathrm{~mL})$ is added and the conical flask is shaken to dissolve the internal solution completely. Then 3 drops of phenolphthalein indicator are added to the conical flask and mixed. Lastly, $0.1 \mathrm{~N}$ solution of potassium hydroxide is titrated to the conical flask to show reddish and to maintain $30 \mathrm{~s}$. Also, the consumption of potassium hydroxide solution $\mathrm{mL}$ number is written down. Finally, oil acid is valued by the form

$$
\operatorname{Acidvalue}(\mathrm{mg} \mathrm{KOH} / \mathrm{g})=\frac{V \times N \times 56.1}{W},
$$

where $V=$ titration consumption potassium hydroxide solution volume $(\mathrm{mL}), N=$ the concentration of $\mathrm{KOH}$ solution $(\mathrm{mol} / \mathrm{L}), 56.1=$ the molar mass of $\mathrm{KOH}(\mathrm{g} / \mathrm{mol})$, and $W=$ sample quality $(\mathrm{g})$. 


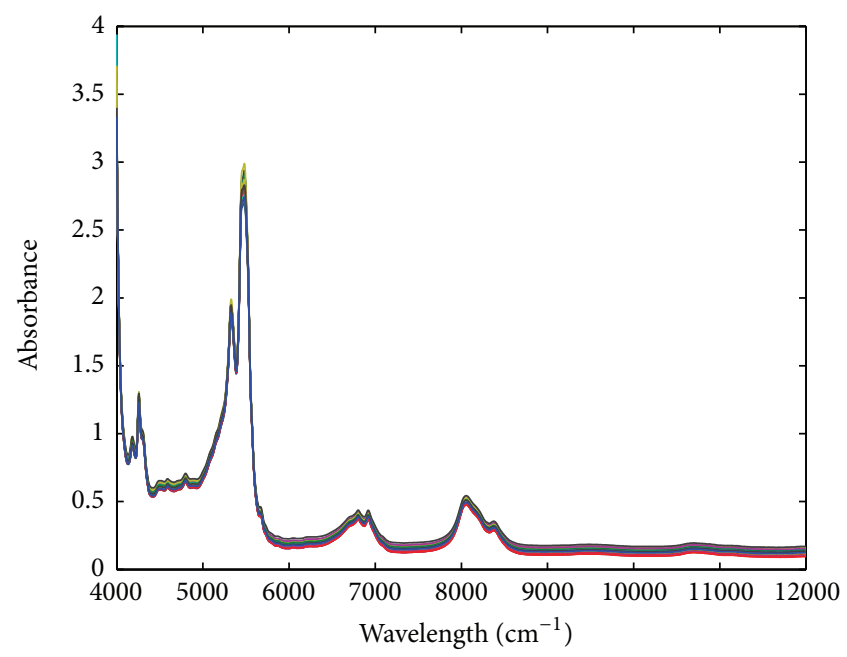

(a) Soybean oil spectrum

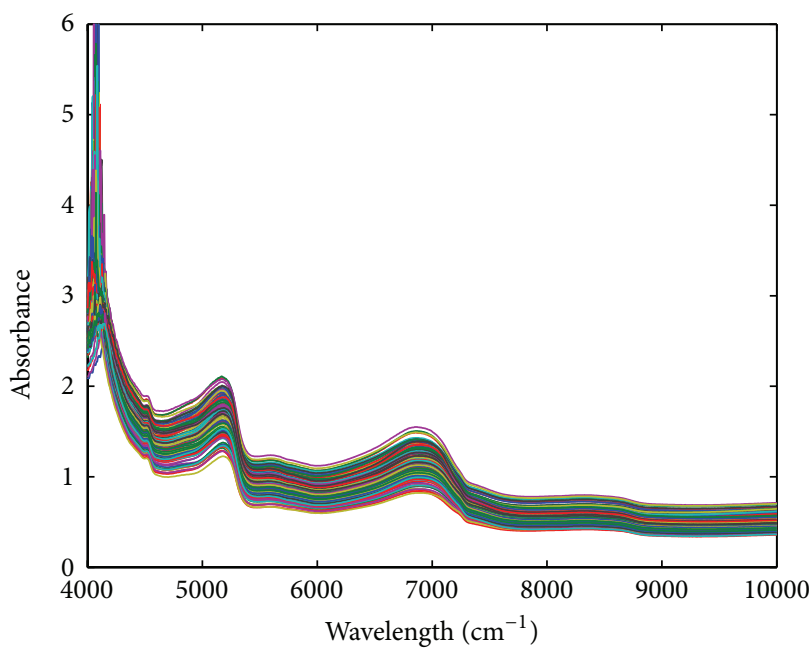

(b) Wheat straw spectrum

FIGURE 1: Soybean oil and wheat straw biomass spectrum.

The experimental results allow the error not to exceed $0.2 \mathrm{mg} \mathrm{KOH} / \mathrm{g}$ and the average is the determination results. The distribution range of oil acid value (52) is measured of $0.473 \sim 3.102 \mathrm{mg} \mathrm{KOH} / \mathrm{g}$.

(2) Fermentation microbial biomass is chosen as the research object in the experiment. Monitoring biomass of bacterial colony, which is measured by glucosamine method, is vital. Its biomass stands for microbial density per unit volume. The preparation and determination process is as follows.

(1) Reagents. Concentrated sulfuric acid, acetyl acetone, sodium hydroxide, peptone, sodium nitrate, magnesium sulfate, potassium dihydrogen phosphate, and dibenzaldehyde are used.

(2) Instruments and Appliances. The following are used: UV3000 UV-visible spectrophotometer, FA1004 electronic balance, and SPX-250B-Z-type incubator.

(3) Operation Calculation. Firstly, dry cell $(0.1 \mathrm{~g})$ is weighed precisely and solid-state fermentation substrate $(0.5 \mathrm{~g})$ with sulfuric acid $(2 \mathrm{~mL} 60 \%)$ is soaked for 24 hours, diluting to $1 \mathrm{~mol} / \mathrm{L}$ then placing into flask $(250 \mathrm{~mL})$ with heating one hour in $9.8 \times 104 \mathrm{~Pa}$ high-pressure. After cooling, diluent is neutralized with sodium hydroxide $(1 \mathrm{~mol} / \mathrm{L})$ to $\mathrm{pH} 7.0$, setting the volume to $100 \mathrm{~mL}$. Secondly, according to Elson Morgan, absorbance is measured at $530 \mathrm{~nm}$ based on five parallel samples per specimen, choosing the average value as the absorbance of the sample. At last, distilled water $(2 \mathrm{~mL})$ was used as a blank cell in measuring the quality of solid-state fermentation matrix glucosamine.

Biomass is estimated as follows:

$$
\begin{aligned}
& \text { Biomass }\left(\frac{\mathrm{mg}}{\mathrm{mg} \text { dry mediu }}\right) \\
& =\frac{\mathrm{C}(\mathrm{mg} / \mathrm{mg} \text { dry mediu })}{\mathrm{B}(\mathrm{mg} / \mathrm{mg} \text { dry mediu })} \times 1000,
\end{aligned}
$$

\begin{tabular}{|c|c|c|c|}
\hline Model & Waveband & Factors & RMSEV \\
\hline \multirow{7}{*}{ Soybean oil } & $4450-9000 \mathrm{~cm}^{-1}$ & 5 & 0.3713605 \\
\hline & $4450-5000 \mathrm{~cm}^{-1}$ & 3 & 0.2910486 \\
\hline & $5300-6200 \mathrm{~cm}^{-1}$ & 8 & 0.4472479 \\
\hline & $6700-7400 \mathrm{~cm}^{-1}$ & 4 & 0.5424621 \\
\hline & $8000-8900 \mathrm{~cm}^{-1}$ & 7 & 0.565388 \\
\hline & $6500-9000 \mathrm{~cm}^{-1}$ & 5 & 0.3875379 \\
\hline & $4450-5000$ and $6700-7400 \mathrm{~cm}^{-1}$ & 4 & 0.3339818 \\
\hline
\end{tabular}

TABLE 4: Waveband selection of soybean oil acid model.

TABLE 5: Waveband selection of wheat straw biomass model.

\begin{tabular}{lccc}
\hline Model & Waveband & Factors & RMSEV \\
\hline & $4500-5500 \mathrm{~cm}^{-1}$ & 22 & 14.545956 \\
Wheat straw & $6500-7500 \mathrm{~cm}^{-1}$ & 8 & 16.910915 \\
& $8000-8900 \mathrm{~cm}^{-1}$ & 6 & 24.439814 \\
& $\mathbf{9 0 0 0 - 1 0 0 0 0 \mathrm { cm } ^ { - 1 }}$ & $\mathbf{6}$ & $\mathbf{1 1 . 8 1 7 7 5 7}$ \\
& $4000-10000 \mathrm{~cm}^{-1}$ & 3 & 17.365391 \\
\hline
\end{tabular}

where $C=$ unit mass culture glucosamine (\%) and $B=$ unit mass of bacteria in the glucosamine content (\%).

\section{Results and Discussion}

Aiming at the acid value model for soybeans and wheat straw biomass, respectively, $X-Y$ model variance, Mahalanobis distance, and Hotelling $T^{2}$ statistics, we compare leverage 3D and $X-Y$ variance method. Meanwhile, we select $4450 \mathrm{~cm}-$ $5000 \mathrm{~cm}^{-1}$ model features band as soybean acid number and $9000 \mathrm{~cm}-10000 \mathrm{~cm}^{-1}$ model features as biomass wheat straw band. Unscrambler 10.2 software and the preparation of the model itself Matlab programming are used to analyze. Waveband selection is shown in Tables 4 and 5. 


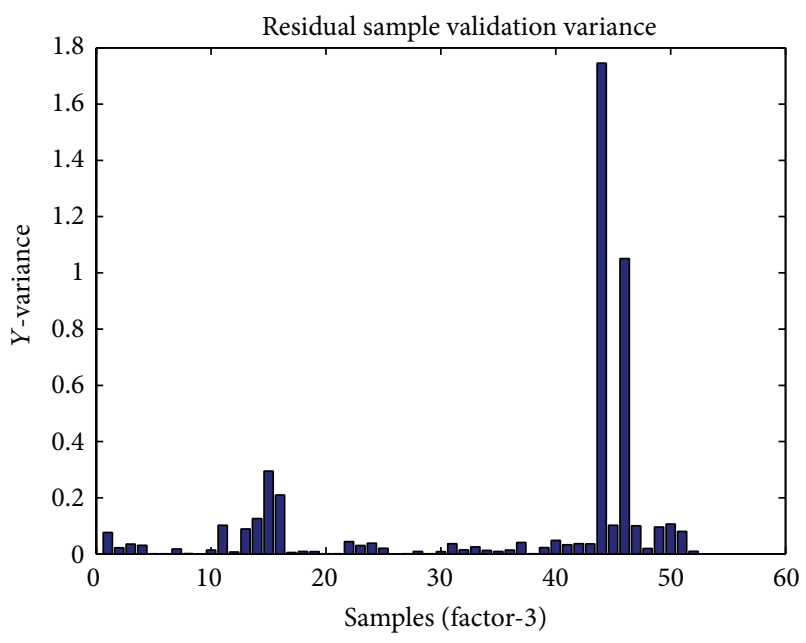

(a) $Y$-variance distribution of the soybean oil model

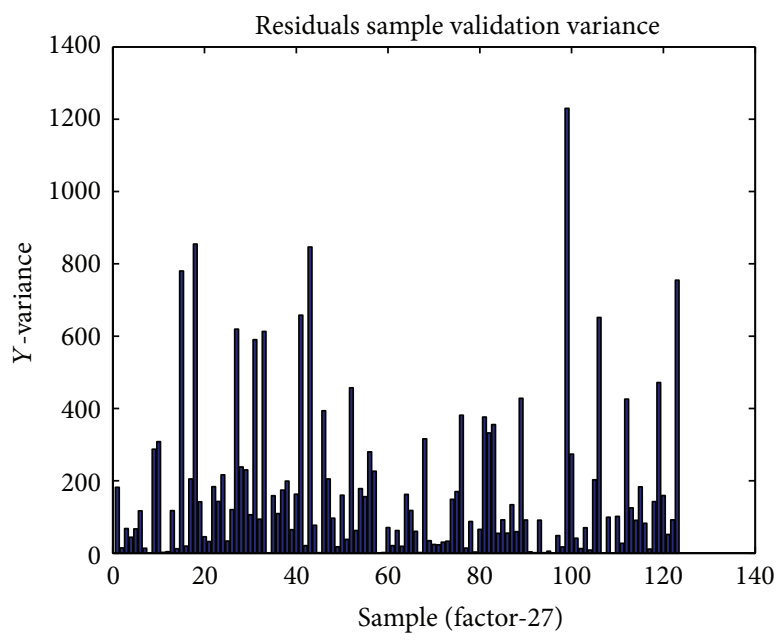

(b) $Y$-variance distribution of the wheat straw biomass model

FIGURE 2: $Y$-variance distribution of the model.

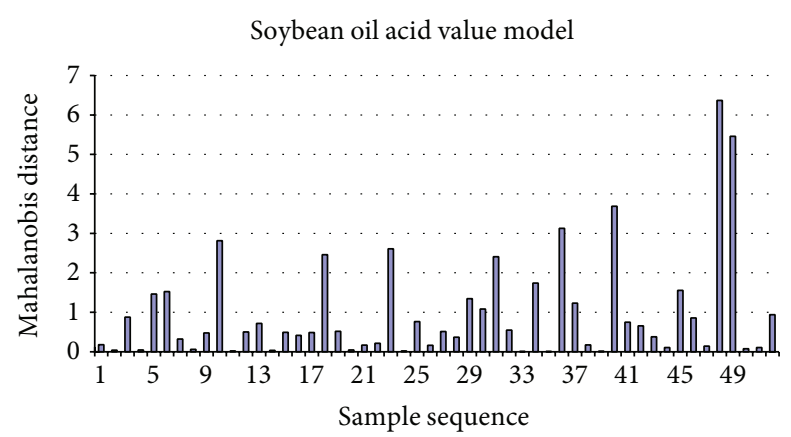

(a) Mahalanobis distance of the soybean oil model

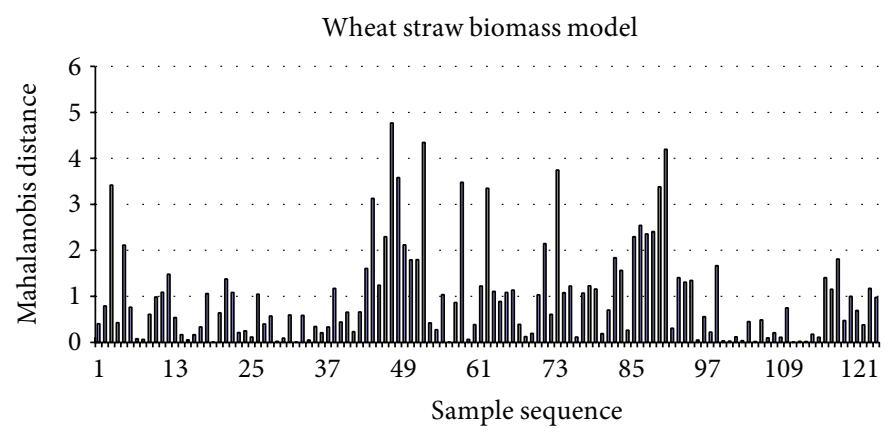

(b) Mahalanobis distance of the wheat straw biomass model

Figure 3: Mahalanobis distance calculations.

3.1. $X-Y$ Variance Analysis. First, the samples for the correction $X-Y$ model of variance were analyzed where $X$ (residual sample $X$-variance) represents sample spectrum and $Y$ (residual sample $Y$-variance) represents the chemical values of samples. Under normal circumstances, the residuals are calculated for the $Y$ : the greater the variance of a sample of $Y$ is, namely, correct model for its ability to fit is weaker, the lower the explanatory power is. From Figure 2, it can be seen that (Figure 1(a) shows the spectrum of acid value of soybean, Figure 1(b) shows the spectrum of wheat straw), in soybean acid value model, two samples, number 44 and number 46 , have significantly higher variance and in biomass straw bran model, four samples, numbers $15,18,43$, and 99 , have a relatively high variance, which can be regarded as outliers (abnormal) samples to be removed.

3.2. Mahalanobis Distance Analysis. In near-infrared spectroscopy, Euclidean distance and Mahalanobis distance are important method for determining the abnormal samples. Compared to the Euclidean distance, Mahalanobis distance as taking into account the links between the various characteristics is widely used. In this experiment, two calibration models were Mahalanobis distance calculation, the calculation results shown in Figure 3. As can be seen from the figure, in the acid value of soybean model, a sample of 52 represents strongly and small differences are in the overall Mahalanobis distance. Maximum distance of two samples numbers 40, 49 is trimmed. In wheat bran straw biomass models, the samples exhibit greater volatility in Mahalanobis distance, where numbers 47,52 , and 90 samples have significant differences and should be considered rejected, due to the messy sample distribution ( $\min 2.9-\max 99.2$ ).

3.3. Hotelling $T^{2}$ Statistical Analysis. Hotelling $T^{2}$ statistics in the multivariate statistical analysis is a kind of important statistics. It is a two-dimensional elliptic model based on Principal Component Analysis (PCA), which is mainly used to test the stability of multivariate. If principal components of all observables are stable, its $T^{2}$ statistic would be maintained at a stable level. Then, abnormal situations are detected by associated critical limit. From the figure, when the limit is 5\%, in the soybean oil acid value model, samples 48,49 obviously deviate from the center of the circle, far beyond the limit, and in the wheat straw bran biomass model, samples 13, 14, and 17 


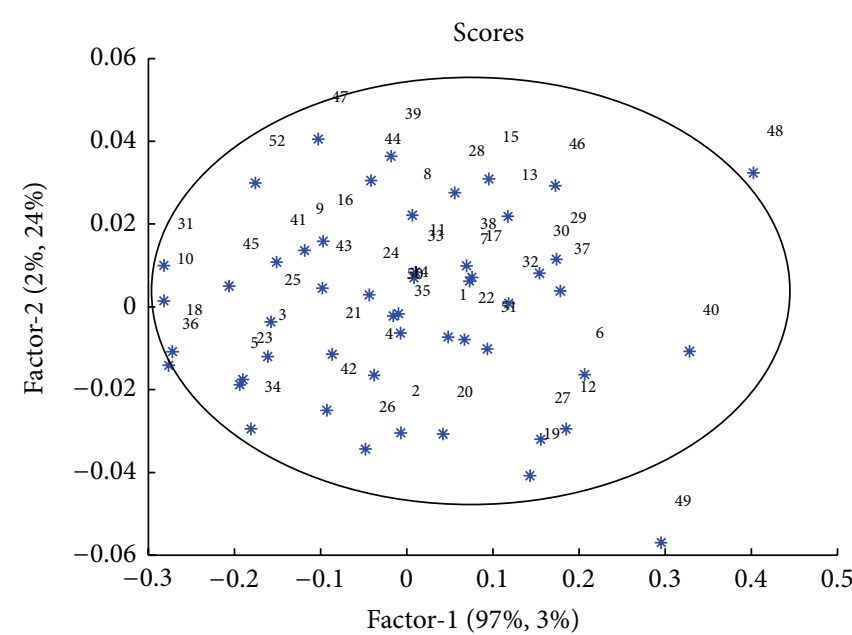

(a) Hotelling $T^{2}$ statistic of the soybean oil model

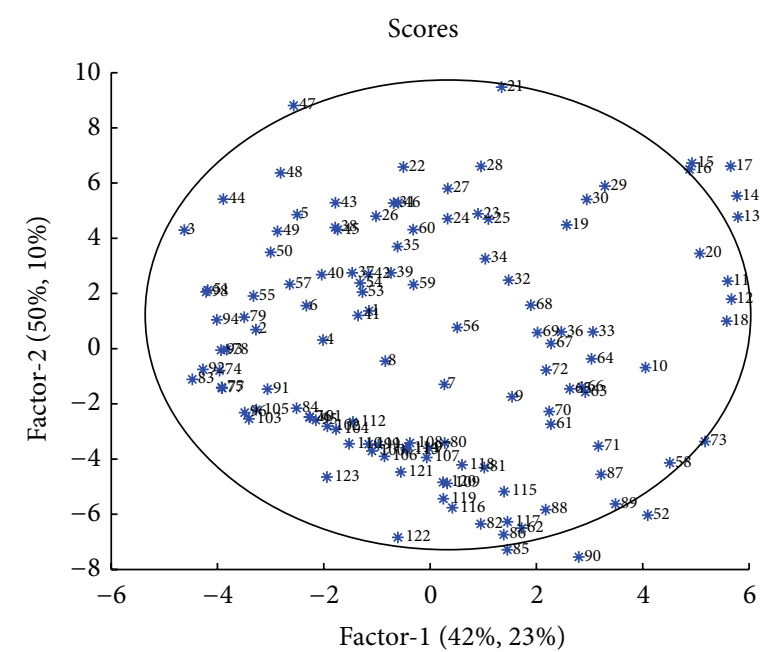

(b) Hotelling $T^{2}$ statistic of the wheat straw biomass model

FIgURE 4: Hotelling $T^{2}$ statistic.

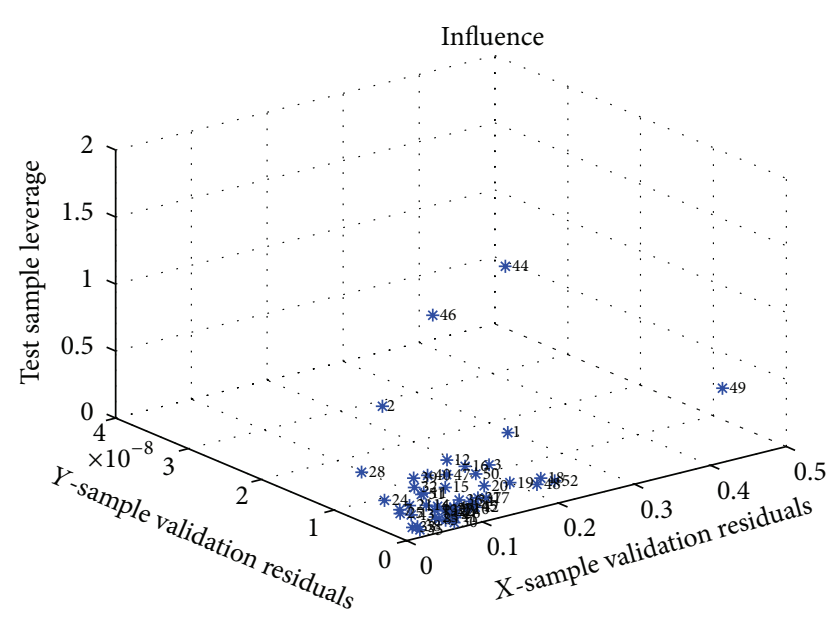

(a) 3D view of $X-Y$ variance and leverage of soybean oil model

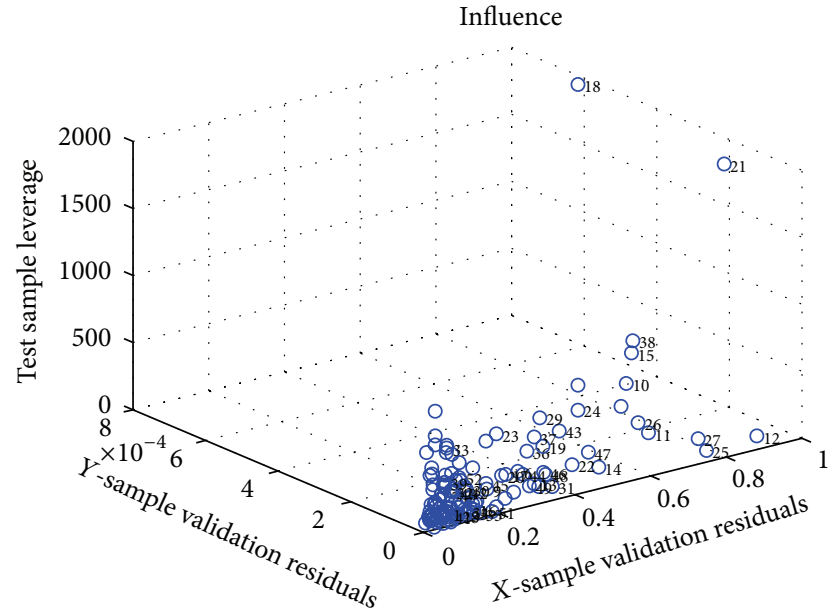

(b) 3D view of $X-Y$ variance and leverage of wheat straw biomass model

Figure 5: 3D view of $X-Y$ variance and leverage.

are also beyond the limit, which can be considered excluded samples from Figure 4.

3.4. 3D View Analysis of X-Y Variance and Leverage Value. Calculate the leverage [32-34] value and $X-Y$ variance [35] value in the model of acid value of soybean and wheat straw biomass, the leverage value is very useful to detect whether the sample is far from the space center of model. Samples with high leverage value are likely to be outliers, which also has a great influence on the model accuracy. The outlier (abnormal) samples to establish the $3 \mathrm{D}$ view of the Leverage and the $X-Y$ variance, which select residual sample $X$-variance as the $x$-axis, leverage (leverage) as the $y$-axis, and residual sample $Y$-variance as the $z$-axis and comprehensive judgments, as can be seen from Figure 5. In the process of the entire model fitting, most of the samples are uniformly distributed in the center of the $3 \mathrm{D}$ view, but a small portion of the samples is far away from the center, and the distance between the center and the far sample of the $X-Y$ variance and the leverage is very large. As shown in Figure 5, it can be seen that the samples 44,46 in the soybean oil acid value model deviate significantly from the center far; the result of its analysis is consistent with the $X-Y$ variance; in the wheat straw bran biomass model, samples 15, 23, 70, and 83 have obvious abnormalities, Determining integrated values in three directions, the above several points can be excluded.

3.5. Model Demonstration. Methods for excluding outliers above sample select cross validation (cross validation) to verify. Figure 6 shows, where soybean oil with 52 samples and 123 samples of wheat straw bran established PLSR (Partial Least Squares Regression) model without any discrete rejection, 


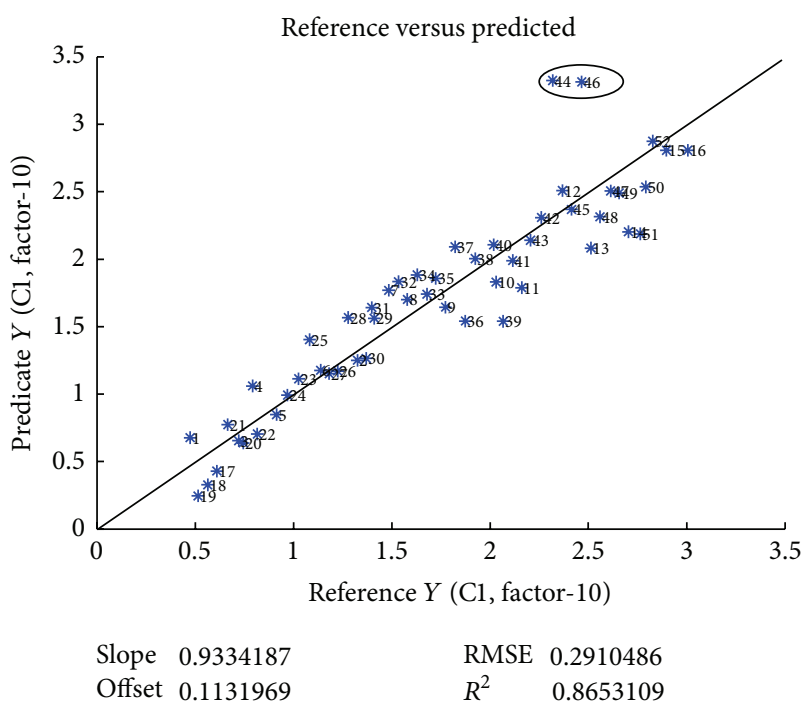

(a) Original spectral modeling of the soybean oil model

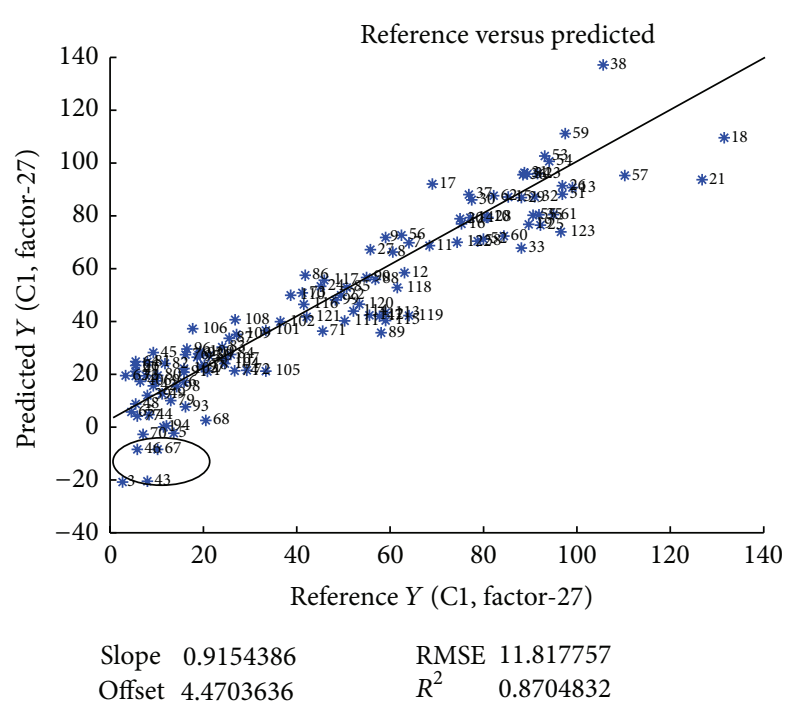

(b) Original spectral modeling of the wheat straw biomass model

FIGURE 6: Original spectral modeling.

we can see that the decision coefficient $R^{2}$ of soybean oil acid value model is 0.8653109 and the value of wheat straw bran biomass model is 0.870438 ; both the coefficients of determination are not high, and from the marked area in the Figure 7 we can see that the samples 44, 46 in the soybean oil acid value model are separated from the entire calibration curve, which is consistent with our previous conclusions. In the wheat straw bran biomass model, because of the existence of some stray samples, the value of sample 1 in the process of fitting is 0 , instead of the original chemical numerical error which is very large.

After various methods for excluding outliers, the accuracy of the model is shown in Table 6. In the soybean oil acid value model, $X-Y$ variance method for selecting outliers is consistent with $3 \mathrm{D}$ view analysis and both the best main factors are 5. However, the accuracy of calibration model after Mahalanobis distance analysis and Hotelling's $T^{2}$ statistics is even slightly lower. In the wheat straw bran biomass model, the best method is based on the 3D view analysis. The best main factor is $27 ; X-Y$ variance, Hotelling's $T^{2}$ statistics, and the Mahalanobis distance methods compared to the original spectrum also have improved.

Through Tables 6 and 7 analysis, it was found that the best two models after excluding outliers are based on $3 \mathrm{D}$ view analysis of $X-Y$ variance and leverage value. In the wheat straw biomass model, the coefficient of determination of calibration $R^{2}$ upgrade to 0.911626 and root mean square error (RMSE) is 9.060135. In practical, we found that the accuracy of the model can be further improved if we repeated the $3 \mathrm{D}$ view analysis. Therefore, according to this idea, we continue to do this work like the above, which in Figure 7(a) is the wheat straw bran biomass model with samples 18, 39, 74 being excluded which in Figure 7 (a) is the Wheat straw bran biomass model with sample 18, 21 are excluded. Figures $7(\mathrm{~b})-7$ (d) for turn samples 27, (9,7), 91, are excluded; the correction model coefficient of determination $R^{2}$ upgrade to
TABLE 6: Soybean oil acid value model after excluding outliers.

\begin{tabular}{lcccc}
\hline Method & $\begin{array}{c}\text { Excluding } \\
\text { outliers }\end{array}$ & Factor & $R^{2}$ & RMSE \\
\hline$X$-Y varianc & 44,46 & 5 & 0.966022 & 0.136879 \\
Mahalanobis distance & 48,49 & 4 & 0.846159 & 0.299031 \\
Hotelling $T^{2}$ & 48,49 & 4 & 0.847478 & 0.292275 \\
3D view analysis & 44,46 & 5 & 0.966022 & 0.136879 \\
\hline
\end{tabular}

TABLE 7: Wheat straw biomass model after excluding outliers.

\begin{tabular}{lcccc}
\hline Method & $\begin{array}{c}\text { Excluding } \\
\text { outliers }\end{array}$ & Factor & $R^{2}$ & RMSE \\
\hline$X-Y$ varianc & $15,18,43,99$ & 27 & 0.905218 & 10.11064 \\
Mahalanobis distance & $47,52,90$ & 27 & 0.872461 & 11.78504 \\
Hotelling $T^{2}$ & $13,14,17$ & 27 & 0.881279 & 11.43546 \\
3D view analysis & 18,21 & 27 & 0.911626 & 9.60135 \\
\hline
\end{tabular}

0.934227 and RMSE reduce to 8.4943037 . It can be seen that the accuracy of the calibration model improved significantly after several times outliers excluding.

\section{Conclusions}

By the soybean oil acid value model and the wheat straw bran biomass model research experiment and comparative analysis to prove that in the near-infrared spectroscopy analysis methods for excluding outliers based on $3 \mathrm{D}$ view analysis of $X-Y$ variance VS leverage are effective, comprehensive analysis and judgment of the methods, residual sample $X$ variance, leverage (leverage), and residual sample $Y$-variance are more comprehensive accurate judgment of abnormal samples and the accuracy of the model improved significantly after several times outliers excluding. This method also for 


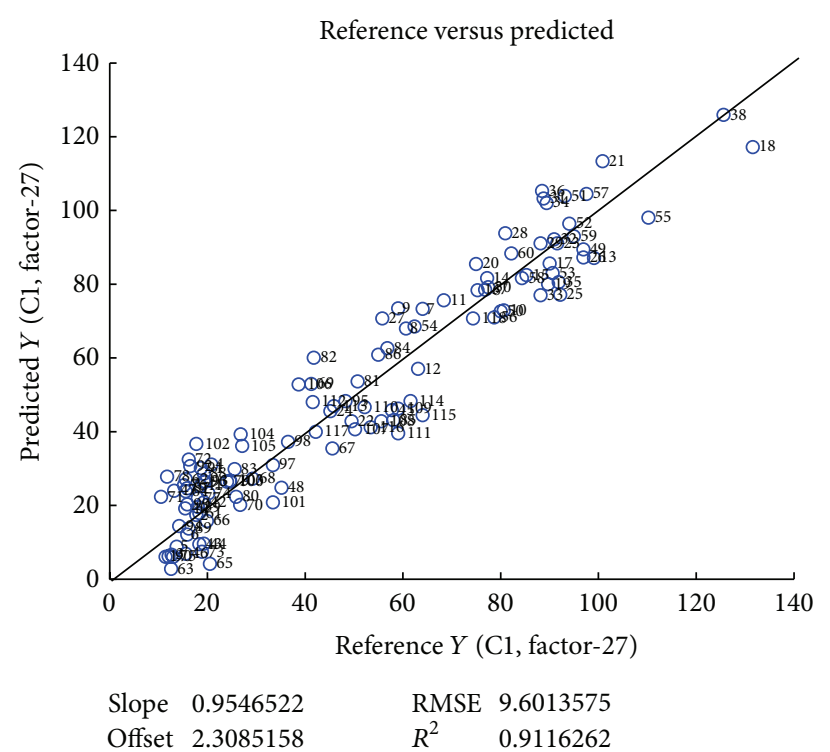

(a) 3D view excluding numbers 18 and 21 samples

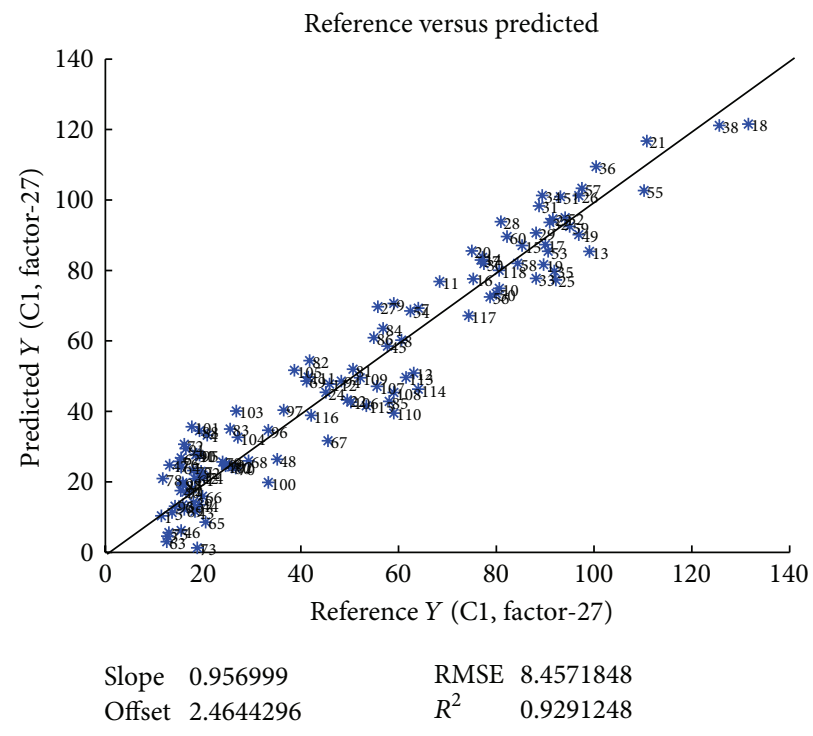

(c) 3D view excluding numbers 9 and 7 samples

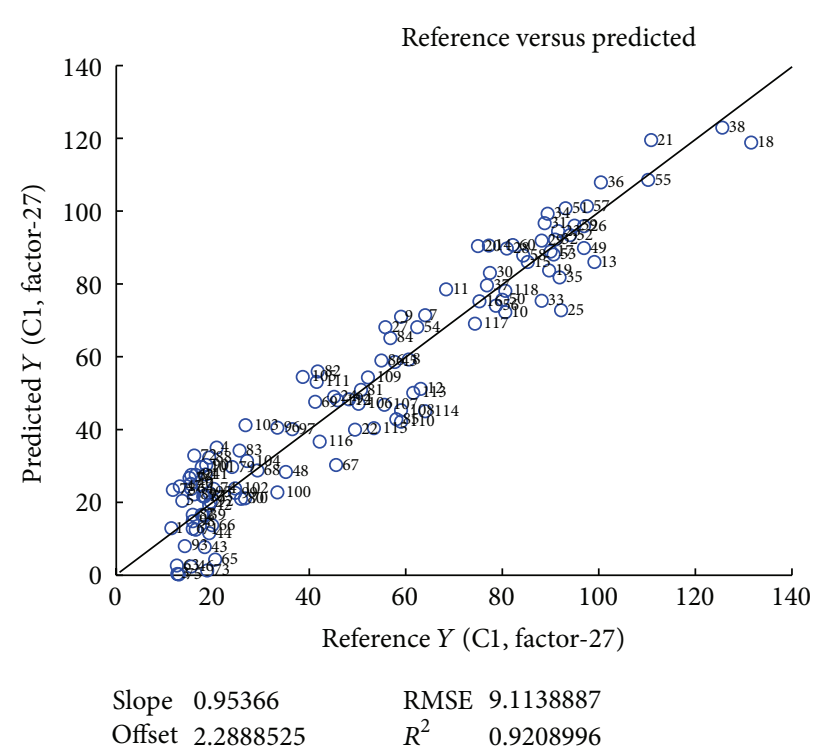

(b) $3 \mathrm{D}$ view excluding number 27 sample

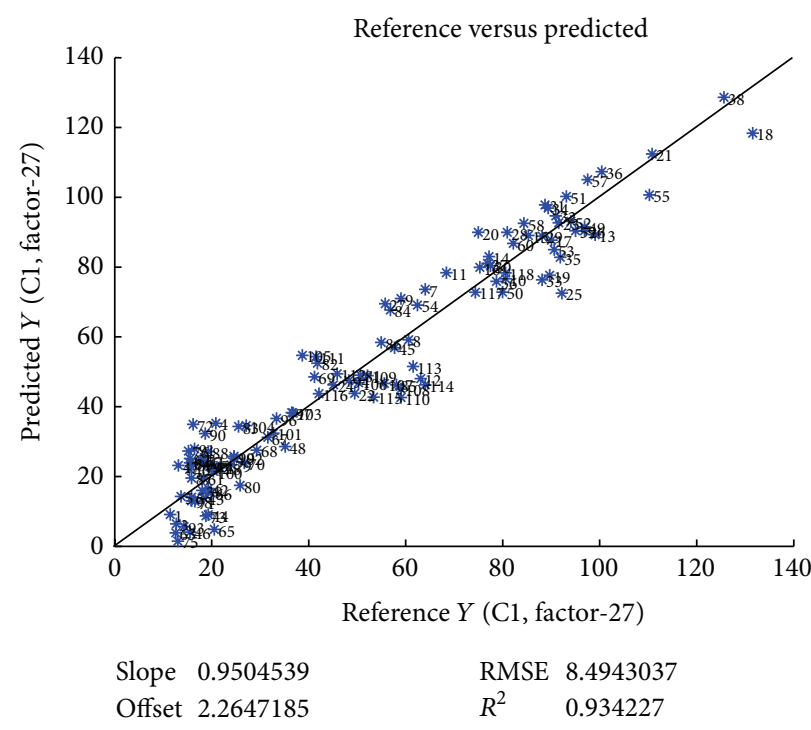

(d) $3 \mathrm{D}$ view excluding number 91 sample

Figure 7: Modeling after excluding the outlier sample.

the future of near-infrared spectroscopy outlier samples excluded proposes a new direction.

\section{Conflict of Interests}

The authors declare that there is no conflict of interests regarding the publication of this paper.

\section{Acknowledgments}

The authors would like to acknowledge the financial support from the National High-tech R\&D Program of China (863 Program) (2013AA102303); Natural Science Foundation of
Heilongjiang Province of China (F201402); and Key Technologies R\&D Program of Harbin (2013AA6BN010).

\section{References}

[1] Y. Vaknin, M. Ghanim, S. Samra et al., "Predicting Jatropha curcas seed-oil content, oil composition and protein content using near-infrared spectroscopy-a quick and non-destructive method," Industrial Crops and Products, vol. 34, no. 1, pp. 10291034, 2011.

[2] L. E. Agelet, P. R. Armstrong, I. R. Clariana, and C. R. Hurburgh, "Measurement of single soybean seed attributes by near-infrared technologies. A comparative study," Journal of Agricultural and Food Chemistry, vol. 60, no. 34, pp. 8314-8322, 2012. 
[3] S. Hou and L. Li, "Rapid characterization of woody biomass digestibility and chemical composition using near-infrared spectroscopy," Journal of Integrative Plant Biology, vol. 53, no. 2, pp. 166-175, 2011.

[4] K. P. Vogel, B. S. Dien, H. G. Jung, M. D. Casler, S. D. Masterson, and R. B. Mitchell, "Quantifying actual and theoretical ethanol yields for switchgrass strains using NIRS analyses," Bioenergy Research, vol. 4, no. 2, pp. 96-110, 2011.

[5] G. Hacisalihoglu, B. Larbi, and A. Mark Settles, "Near-infrared reflectance spectroscopy predicts protein, starch, and seed weight in intact seeds of common bean (Phaseolus vulgaris L.)," Journal of Agricultural and Food Chemistry, vol. 58, no. 2, pp. 702-706, 2010.

[6] M. M. Blanke, "Non-invasive assessment of firmness and NIR sugar (TSS) measurement in apple, pear and kiwi fruit," Erwerbs-Obstbau, vol. 55, no. 1, pp. 19-24, 2013.

[7] Y. Liu, X. Sun, H. Zhang, and O. Aiguo, "Nondestructive measurement of internal quality of Nanfeng mandarin fruit by charge coupled device near infrared spectroscopy," Computers and Electronics in Agriculture, vol. 71, supplement 1, pp. S10-S14, 2010.

[8] H. Yang, "Remote sensing technique for predicting harvest time of tomatoes," Procedia Environmental Sciences, vol. 10, pp. 666671, 2011.

[9] L. Liu, X. P. Ye, A. R. Womac, and S. Sokhansanj, "Variability of biomass chemical composition and rapid analysis using FT-NIR techniques," Carbohydrate Polymers, vol. 81, no. 4, pp. 820-829, 2010 .

[10] L. Esteve Agelet, D. D. Ellis, S. Duvick, A. S. Goggi, C. R. Hurburgh, and C. A. Gardner, "Feasibility of near infrared spectroscopy for analyzing corn kernel damage and viability of soybean and corn kernels," Journal of Cereal Science, vol. 55, no. 2, pp. 160-165, 2012.

[11] P. V. Anderson, B. J. Kerr, T. E. Weber, C. J. Ziemer, and G. C. Shurson, "Determination and prediction of digestible and metabolizable energy from chemical analysis of corn coproducts fed to finishing pigs," Journal of Animal Science, vol. 90, no. 4, pp. 1242-1254, 2012.

[12] P. R. Armstrong, J. G. Tallada, C. Hurburgh, D. F. Hildebrand, and J. E. Specht, "Development of single-seed near-infrared spectroscopic predictions of corn and soybean constituents using bulk reference values and mean spectra," Transactions of the ASABE, vol. 54, no. 4, pp. 1529-1535, 2011.

[13] G. L. Chen, B. Zhang, J. G. Wu, and C. H. Shi, "Nondestructive assessment of amino acid composition in rapeseed meal based on intact seeds by near-infrared reflectance spectroscopy," Animal Feed Science and Technology, vol. 165, no. 1-2, pp. 111119, 2011.

[14] L. Chen, Z. Yang, and L. Han, "A review on the use of nearinfrared spectroscopy for analyzing feed protein materials," Applied Spectroscopy Reviews, vol. 48, no. 7, pp. 509-522, 2013.

[15] P. Cozannet, Y. Primot, C. Gady et al., "Energy value of wheat distillers grains with solubles for growing pigs and adult sows," Journal of Animal Science, vol. 88, no. 7, pp. 2382-2392, 2010.

[16] P. F. Zhang, Q. Zhang, T. W. Deines, Z. J. Pei, and D. H. Wang, "Ultrasonic vibration-assisted pelleting of wheat straw: a designed experimental investigation on pellet quality and sugar yield," Journal of Manufacturing Science and Engineering, Transactions of the ASME, vol. 134, no. 6, Article ID 61013, 2012.

[17] H. Wang, X. Wu, and D. Wang, "Acid-functionalized magnetic nanoparticle as catalyst for biodiesel synthesis," American
Chemical Society Division of Energy \& Fuels, vol. 57, pp. 177-178, 2012.

[18] S. Jin and H. Chen, "Near-infrared analysis of the chemical composition of rice straw," Industrial Crops and Products, vol. 26, no. 2, pp. 207-211, 2007.

[19] G. Qi, N. Li, D. Wang, and X. S. Sun, "Physicochemical properties of soy protein adhesives obtained by in situ sodium bisulfite modification during acid precipitation," Journal of the American Oil Chemists' Society, vol. 89, no. 2, pp. 301-312, 2012.

[20] B. J. Kerr, W. A. Dozier III, and G. C. Shurson, "Effects of reduced-oil corn distillers dried grains with solubles composition on digestible and metabolizable energy value and prediction in growing pigs," Journal of Animal Science, vol. 91, no. 7, pp. 3231-3243, 2013.

[21] S. Yan, X. Wu, J. Faubion et al., "Ethanol-production performance of ozone-treated tannin grain sorghum flour," Cereal Chemistry, vol. 89, no. 1, pp. 30-37, 2012.

[22] A. Al-Alawi, F. R. Van De Voort, and J. Sedman, "A new Fourier transform infrared method for the determination of moisture in edible oils," Applied Spectroscopy, vol. 59, no. 10, pp. 1295-1299, 2005.

[23] F. R. van de voort, J. Sedman, and S. T. Sherazi, "Improved FTIR trans analysis in edible oils using spectral reconstitution," Journal of AOAC International, vol. 90, pp. 446-451, 2007.

[24] C. J. Lomborg, M. H. Thomsen, E. S. Jensen, and K. H. Esbensen, "Power plant intake quantification of wheat straw composition for 2nd generation bioethanol optimization-a Near Infrared Spectroscopy (NIRS) feasibility study," Bioresource Technology, vol. 101, no. 4, pp. 1199-1205, 2010.

[25] H. Jiang, G. Liu, X. Xiao, C. Mei, Y. Ding, and S. Yu, "Monitoring of solid-state fermentation of wheat straw in a pilot scale using FT-NIR spectroscopy and support vector data description," Microchemical Journal, vol. 102, pp. 68-74, 2012.

[26] P. Kaparaju and C. Felby, "Characterization of lignin during oxidative and hydrothermal pre-treatment processes of wheat straw and corn stover," Bioresource Technology, vol. 101, no. 9, pp. 3175-3181, 2010.

[27] F. Xu, J. Yu, T. Tesso, F. Dowell, and D. Wang, "Qualitative and quantitative analysis of lignocellulosic biomass using infrared techniques: a mini-review," Applied Energy, vol. 104, pp. 801809, 2013.

[28] S. Bruun, J. W. Jensen, J. Magid, J. Lindedam, and S. B. Engelsen, "Prediction of the degradability and ash content of wheat straw from different cultivars using near infrared spectroscopy," Industrial Crops and Products, vol. 31, no. 2, pp. 321-326, 2010.

[29] H. Luo, Q. Luo, and H. Ding, "Southern jujube quality nearinfrared spectroscopy online model parameters," Spectroscopy, vol. 32, no. 5, pp. 1225-1229, 2012.

[30] F. Xu and D. Wang, "Rapid determination of sugar content in corn stover hydrolysates using near infrared spectroscopy," Bioresource Technology, vol. 147, pp. 293-298, 2013.

[31] F. Dowell, D. Wang, X. Wu, and K. Dowell, "Detecting the antimalarial artemisinin in plant extracts using near-infrared spectroscopy," American Journal of Agricultural Science and Technology, vol. 2, no. 1, pp. 1-7, 2014.

[32] A. Belanche, M. R. Weisbjerg, G. G. Allison, C. J. Newbold, and J. M. Moorby, "Estimation of feed crude protein concentration and rumen degradability by Fourier-transform infrared spectroscopy," Journal of Dairy Science, vol. 96, no. 12, pp. 7867-7880, 2013. 
[33] S. Yan, X. Wu, S. R. Bean et al., "Evaluation of waxy grain sorghum for ethanol production," Cereal Chemistry, vol. 88, no. 6, pp. 589-595, 2011.

[34] Y. Ai, J. Medic, H. Jiang, D. Wang, and J.-L. Jane, "Starch characterization and ethanol production of sorghum," Journal of Agricultural and Food Chemistry, vol. 59, no. 13, pp. 73857392, 2011.

[35] N. Li, Y. Wang, M. Tilley et al., "Adhesive performance of sorghum protein extracted from sorghum DDGS and flour," Journal of Polymers and the Environment, vol. 19, no. 3, pp. 755765, 2011. 


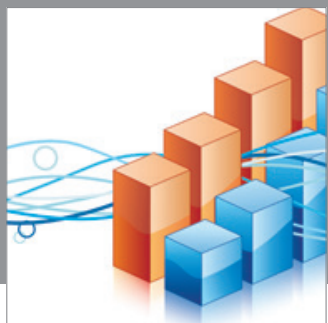

Advances in

Operations Research

mansans

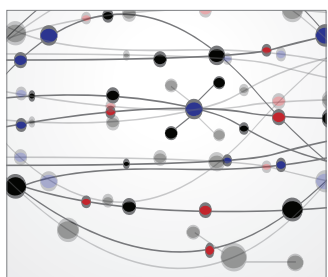

The Scientific World Journal
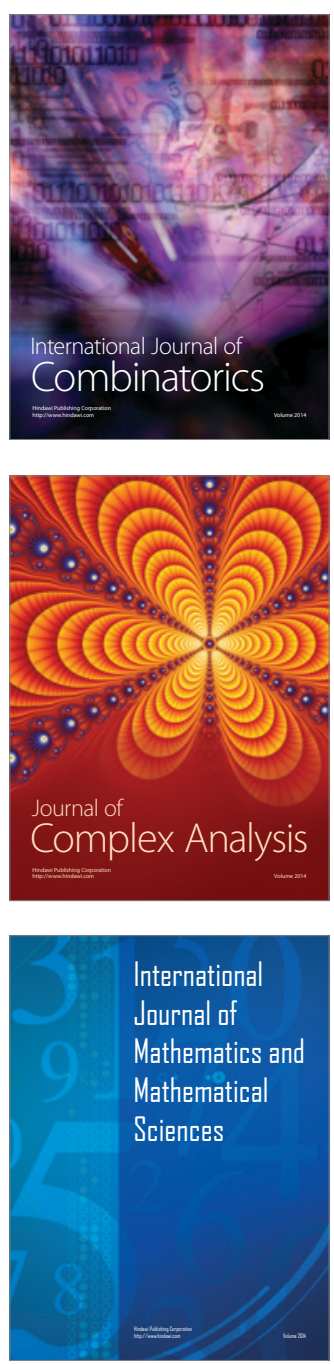
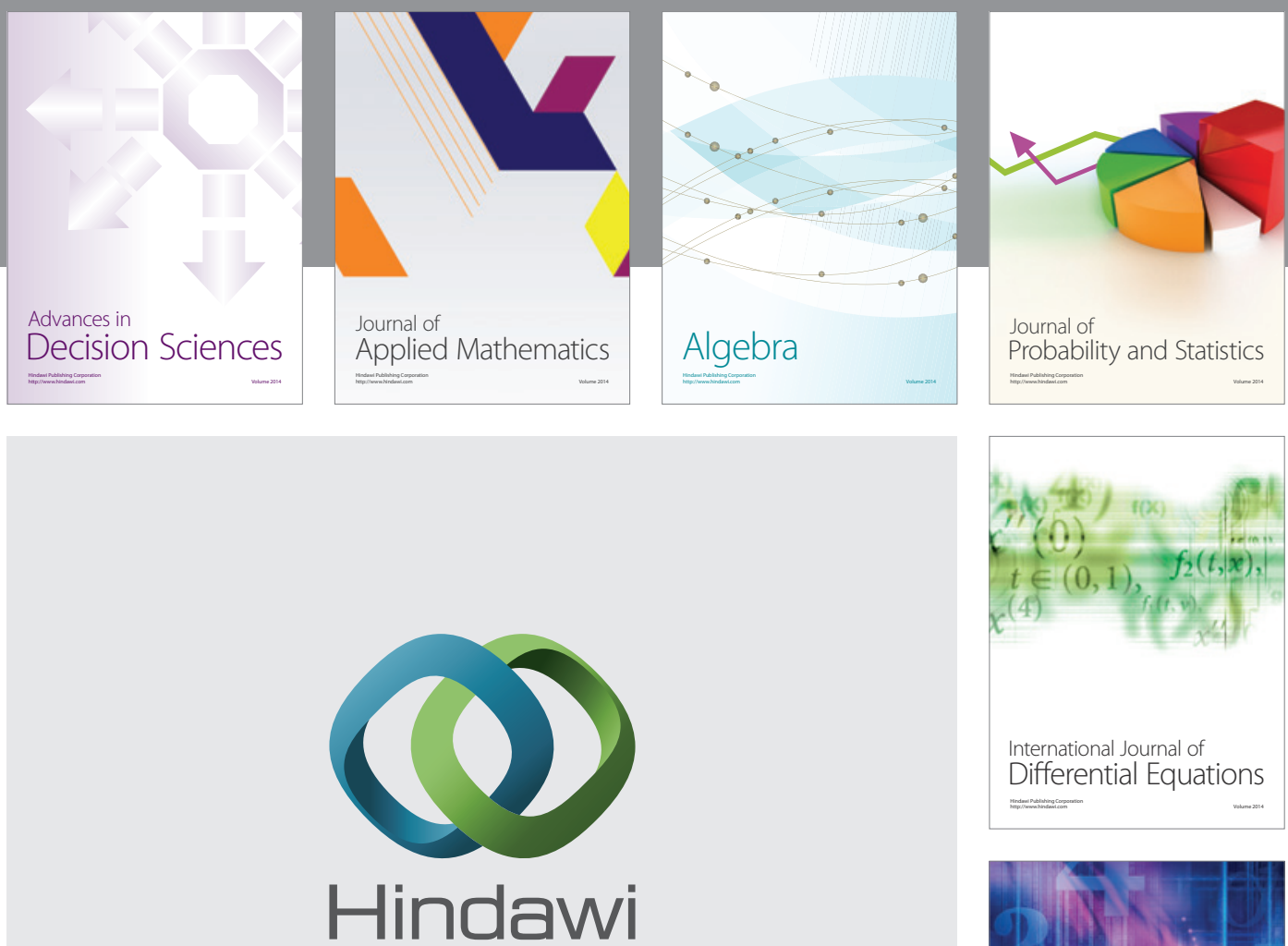

Submit your manuscripts at http://www.hindawi.com
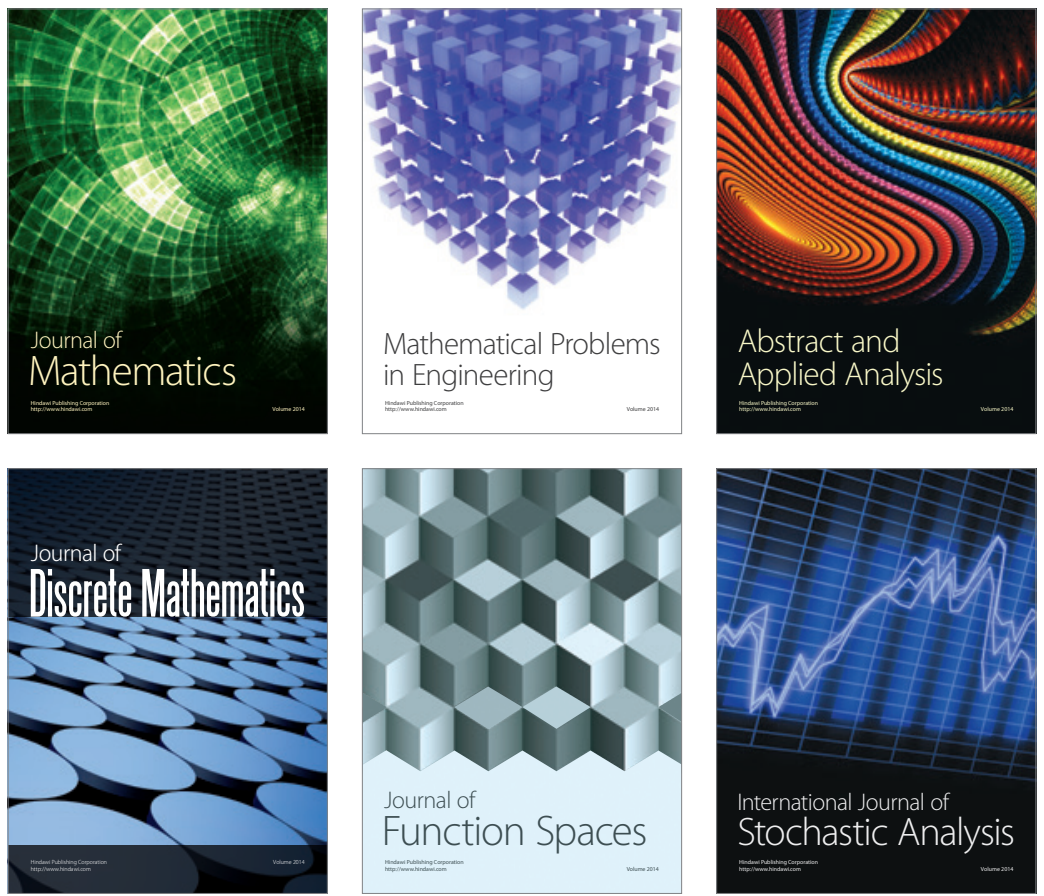

Journal of

Function Spaces

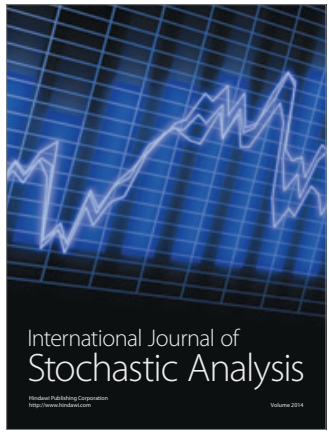

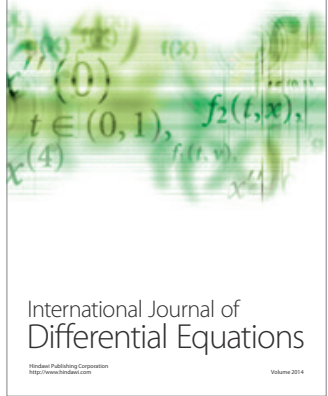
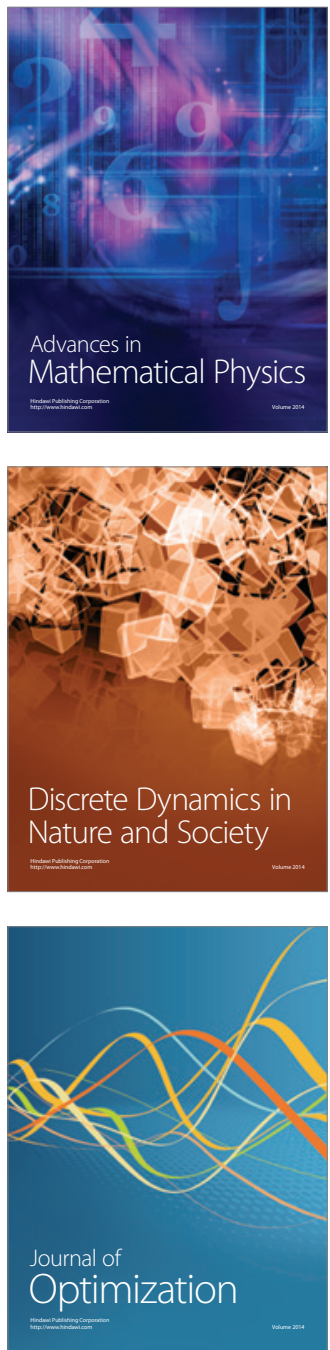